\title{
JuSt - a multimodal program for treatment of insomnia in adolescents: a pilot study
}

\author{
This article was published in the following Dove Press journal: \\ Nature and Science of Sleep \\ 22 December 2010 \\ Number of times this article has been viewed
}

\section{Angelika A Schlarb \\ Christina C Liddle \\ Martin Hautzinger \\ Faculty of Science, Department of Psychology, University of Tuebingen, Tuebingen, Germany}

Correspondence: Angelika A Schlarb Faculty of Science, Department of Psychology, University of Tuebingen, Christophstr 2, 72072

Tuebingen, Germany

$\mathrm{Tel}+49$ 707। 2977185

Fax +49 707। 295219

Email angelika.schlarb@uni-tuebingen.de

\begin{abstract}
Insomnia is the most prevalent sleep disorder in adolescents. A number of studies have evaluated the efficacy of the management of chronic insomnia in adults. Behavioral therapy for insomnia is the treatment of first choice, encompassing education about sleep and sleep hygiene, stimulus control, relaxation techniques, and cognitive strategies to combat nocturnal ruminations. Special programs for adolescents are lacking. In this study an age-oriented treatment program for adolescents (JuSt) was developed and evaluated. Eighteen adolescents and their parents participated in a psychological short-term treatment comprising six sessions. First results show that the treatment was well accepted by the adolescents and their parents and led to a significant reduction in sleep problems, such as sleep onset, sleep efficacy, sleep duration, and feeling rested as well as in cognitive parameters, such as ruminations and mental health. Randomized controlled studies are needed to evaluate the efficacy of this new approach to treat insomnia in adolescents.
\end{abstract}

Keywords: youth, sleep disorder, behavioral treatment, intervention, adolescents, group therapy, hypnotherapy

\section{Introduction}

Insomnia is undoubtedly one of the more common disorders of modern life. In recent years a growing number of clinicians have reported incidences of insomnia, narcolepsy, apnea, and delayed sleep phases in adolescents. ${ }^{1}$ Hence, sleep disorders affect not only adults but also teenagers.

The risk of suffering from sleep disturbances and concomitant daytime consequences increases during adolescence. This rise in risk is attributed to numerous factors, such as biological maturing of the sleep-wake cycle or psychosocial changes during puberty (eg, increase in academic and social demands and opportunities, poor life habits). ${ }^{2-5}$

Prevalence estimations of insomnia in adolescents vary considerably. This is due to several factors: first, the lack of consistent standards defining the disorder; second, the investigation of different age-groups, and third, the use of different approaches concerning the evaluation of co-morbid medical and psychiatric disorders in epidemiological surveys. Depending on the applied definitions epidemiological surveys estimate that the prevalence of any type of insomnia in adolescents varies between $2.1 \%$ and $60 \%$. $^{3,6}$

According to studies that have incorporated stringent criteria, approximately $30 \%$ of adolescents between the ages of 13 and 25 years suffered from a sleep disorder ${ }^{7}$ and approximately $4 \%$ to $9.5 \%$ from insomnia. ${ }^{8,9}$ Different studies show that teenagers do 
not necessarily grow out of their sleep disorder. Hence, sleep disorders in adolescents are not simply a transient problem but tend to become chronic, sometimes even reaching into adulthood. ${ }^{8,10-12}$

The consequences of sleep disorders in adolescents are serious, ranging from somatic problems to significant behavioral concerns and academic failure. Adolescents with symptoms of insomnia have been found to suffer from a lack of energy, fatigue, somatic symptoms like headache, stomach-ache, backache, and poor health in general. ${ }^{3,13,14}$ Different studies (mostly cross-sectional) suggest that sleep problems are associated with emotional instability, depression, anxiety, irritability, fearfulness, anger, tenseness, inattention, conduct problems, drug use, and alcohol use..$^{3,13-18}$ Furthermore, a connection is reported between sleep problems and higher rates of suicidal thoughts and action. ${ }^{14,19}$ Results of a longitudinal study showed that the occurrence of insomnia symptoms at baseline increased the odds of dysfunction a year later on average 2.5 times with regard to 11 indicators of psychological, somatic, and interpersonal functioning. ${ }^{20}$

These findings suggest the need for comprehensive programs to treat and prevent sleep problems in adolescents.

Table I The JuSt-training: contents of the sessions for adolescents and their parents

\begin{tabular}{|c|c|c|c|}
\hline Session Nr & Adolescents/parents & Topic of the session & Contents \\
\hline I & Adolescents & $\begin{array}{l}\text { Welcome to the sleep lab, } \\
\text { Lab for healthy and } \\
\text { disturbed sleep }\end{array}$ & $\begin{array}{l}\text { Introduction } \\
\text { - Sleep doc, sleep lab, lab rules, reward system } \\
\text { Lab for healthy sleep - sleep architecture } \\
\text { - Why do we sleep? } \\
\text { Lab for disturbed sleep - sleep disorders } \\
\text { - prevalence } \\
\text { - contributing factors } \\
\text { - consequences of sleep disorders } \\
\text { Lab for hypnosis - what is hypnotherapy? } \\
\text { - Trance "Sleep Tree" }\end{array}$ \\
\hline 2 & Adolescents & Lab for sleep hygiene & $\begin{array}{l}\text { Experiences of exercises } \\
\text { Lab for sleep hygiene } \\
\text { Trance "Self-hypnosis" }\end{array}$ \\
\hline 3 & Parents & Sleep and parental behavior & $\begin{array}{l}\text { Sleep and sleep disorders } \\
\text { Consequences of sleep problems } \\
\text { Parental behavior and sleep } \\
\text { Lab for stimulus control } \\
\text { - how to create a new sleep ambience }\end{array}$ \\
\hline 4 & Adolescents & $\begin{array}{l}\text { Lab for sleep } \\
\text { environment and ambience, } \\
\text { sleep lab for bedtime rituals }\end{array}$ & $\begin{array}{l}\text { Experiences of exercises } \\
\text { Stimulus control - how to create a new sleep ambience } \\
\text { - Bedtime rituals } \\
\text { Lab for sleep hygiene - influence of substances (caffeine, } \\
\text { alcohol, drugs, medications, etc), sports and nutrition } \\
\text { - Trance "Red Balloon" }\end{array}$ \\
\hline 5 & Adolescents & Lab for anxieties and sorrows & $\begin{array}{l}\text { Experiences of exercises } \\
\text { How can anxieties and sorrows disturb one's sleep } \\
\text { - strategies against anxieties and sorrows } \\
\text { - rumination time and rumination area } \\
\text { - my sorrow box } \\
\text { - transforming negative thoughts into positive ones } \\
\text { - Trance "The Ball" }\end{array}$ \\
\hline 6 & Adolescents & $\begin{array}{l}\text { Lab for stress, } \\
\text { my private sleep lab }\end{array}$ & $\begin{array}{l}\text { Experiences of exercises } \\
\text { Lab for sleep and stress -What stresses me? } \\
\text { - How can stress disturb one's sleep? } \\
\text { - stress-o-meter } \\
\text { - How can I reduce stress? } \\
\text { - problem-solving strategies } \\
\text { Lab for relaxation: progressive muscle relaxation } \\
\text { Trance "Self-hypnosis" } \\
\text { My private sleep lab - what's in it? } \\
\text { Quiz: "Who will be the sleepionaire?" }\end{array}$ \\
\hline
\end{tabular}


So far, only few studies have focused on the treatment of sleep disorders in adolescents and most of them referred to single case studies or interventions for children and adolescents with special needs ${ }^{21}$ or substance abuse. ${ }^{22}$ Most of the existing adolescent sleep-programs were originally designed to prevent sleep problems rather than to treat them. A few examples of sleep education programs are the "Sleep Smart Pacesetter Program" 23 or the "Star Sleeper Campaign". ${ }^{24}$ Moseley and Gradisar implemented a 4-hour school-based intervention to increase sleep knowledge and to improve adolescent sleep problems with significant benefits. ${ }^{25}$ These social learning-based approaches were installed in schools and focus on changing and/or preventing problematic sleepwake behaviors in adolescents.

Altogether, for the age group of adolescents there is a shortage of evaluated group-treatment for primary insomnia. To fill this gap, a multimodal sleep treatment for adolescents aged 11 to 17 years was developed. To our knowledge this is the first program for adolescents with sleep problems involving both behavioral and guided imagery or hypnotherapeutic elements. We hypothesized that the applied techniques would help the adolescents overcome the diversity of sleep-related problems, such as concerns, problems with sleep hygiene as well as relaxation difficulties. Furthermore, we assumed that the program's age-oriented structure would yield a high attendance rate. Above all, we expected a significant change in typical insomnia-related outcomes, such as reduced sleep onset latency, improved sleep efficiency, and increased total sleep time.

\section{Materials and methods Conception of the multimodal treatment program "JuSt"}

The multimodal sleep treatment for adolescents aged 11 to 17 years $\mathrm{JuSt}^{26}$ was developed and administered by the researcher being a qualified and registered psychologist. The sleep treatment is a six-session, multimodal, small-group treatment with 4 to 8 adolescents in each group. Five sessions are conducted for the adolescents and one for their parents. Each weekly session has a duration of 100 minutes.

Versatile treatment components known to be effective in the treatment of insomnia were selected to suit different needs and preferences and therefore to have maximal impact on sleep problems in teenagers. Treatment of adolescent sleep problems largely relies on the adaptation of successful treatment methods for adults. ${ }^{22,27}$ The components include psychoeducation about sleep and sleep disorders, stimulus control instructions, sleep hygiene education ${ }^{28}$ including the regularization of bedtime/ wake-time routine through the week, ${ }^{29}$ cognitive therapy, ${ }^{30}$ hypnotherapy, ${ }^{31}$ and progressive muscle relaxation. ${ }^{32}$ To enhance the teenagers' motivation we designed the program as a creative game: participants enter a fictional sleep lab with a sleep doctor who introduces them into all sleep-related topics and strategies. The adolescents are instructed to act as assistants and study the benefits of these strategies during the week. Each treatment session starts with a short warm-up game and ends with the rehearsal of an imaginative or hypnotherapeutic procedure (trance). Participants are asked to practice these trances between the sessions. Table 1 provides an overview of the treatment and the principal topics of each session.

\section{Participants}

Participants were recruited through doctor's surgeries, outreach clinics, schools, newspaper articles, information evenings, and the official website of the University of Tuebingen. The target population consisted of non-institutionalized adolescents aged 11 to 16 years $(\mathrm{M}=13.73, \mathrm{SD}=1.58)$. Eighteen adolescents with sleep problems, 8 males and 10 females as well as their parents, took part in the study. All adolescents were in public schools. Most of them had one or more siblings (88.9\%).

Each diagnosis was examined in association with sociodemographic information, medical history, use of alcohol, tobacco, and/or coffee, medication intake, life stress, sleep-related breathing disorders, circadian rhythm sleep disorders, parasomnias, sleep-related movement disorders, and diagnoses of mental disorders according to DSM-IV. ${ }^{33}$ According to the International Classification of Sleep Disorders 2 nd edition (ICSD-2) insomnia had to be present for at least 1 month. ${ }^{34}$

About $67 \%$ reported sleep problems during infancy and childhood, and $83.3 \%$ of the adolescents indicated to have been suffering from insomnia symptoms for more than a year (Table 2). None of the adolescents had a mental disorder.

Table 2 Adolescents' main and secondary diagnoses

\begin{tabular}{|c|c|c|c|c|}
\hline \multirow[t]{2}{*}{ ICSD-2 sleep disorders } & \multicolumn{2}{|c|}{ Main diagnosis } & \multicolumn{2}{|c|}{$\begin{array}{l}\text { Secondary } \\
\text { diagnosis }\end{array}$} \\
\hline & $N(18)$ & Percent & $\mathbf{N}$ & Percent \\
\hline $\begin{array}{l}\text { Psychophysiological } \\
\text { insomnia }\end{array}$ & 9 & 50.00 & 5 & 27.78 \\
\hline $\begin{array}{l}\text { Insomnia because of } \\
\text { inadequate sleep hygiene }\end{array}$ & 7 & 38.89 & 9 & 50.00 \\
\hline $\begin{array}{l}\text { Behavioral insomnia } \\
\text { of childhood }\end{array}$ & 2 & II.II & 6 & 33.33 \\
\hline Somnambulism & 0 & 0 & I & 5.55 \\
\hline Nightmares & 0 & 0 & 2 & II.II \\
\hline
\end{tabular}

Note: Several adolescents had more than one additional sleep disorder. Abbreviation: ICSD-2, International Classification of Sleep Disorders 2nd edition. 


\section{Design}

The study aimed to investigate the acceptance and effectiveness of the JuSt intervention program using a pre-post design. Outcome measures were sleep behavior measures, daytime sleepiness, and emotional behavior as well as a post-session qualitative feedback form for both adolescents and parents.

Ethics approval for the research project was obtained from the ethics committee of the university. All adolescents and parents had to give their consent for the study.

\section{Procedure}

At the beginning of the diagnostic procedure both adolescents and parents were asked to complete separately a screeningquestionnaire and the Sleep Disturbance Scale for Children $(\mathrm{SDSC})^{35}$ as well as a sleep diary with regard to the teenagers' sleep. Furthermore, adolescents completed the Youth Self Report whereas the parents filled out the Child Behavior Checklist as standardized forms to describe the children's behavioral and emotional problems. Subsequently, a sleep disorder interview according to the ICSD- 2 criteria $^{34}$ in conjunction with a sleep questionnaire, both specifically designed for this study, were used to perform the diagnostic investigation with adolescents and parents separately. The interview was conducted by two trained interviewers. To rule out the presence of another mental disorder, which might be causing the sleep disorder, we conducted the Anxiety Disorders Interview Schedule-Revised ${ }^{36}$ in a German version for Children and Adolescents. ${ }^{37}$ In addition, parents and adolescents were briefed on the sleep-training. Altogether the interview including the briefing lasted between 60 and 90 minutes.
After the diagnostic procedure the adolescents started with the treatment. Each treatment group was supervised by one behavioral therapist and one advanced graduate student, both of whom had training in behavioral treatment of insomnia, and one of whom had training in hypnotherapy. Two weeks after treatment the adolescents as well as their parents were seen for post-measurement measurement (See Figure 1).

\section{Instruments \\ JuSt - sleep questionnaire}

The questionnaire consists of socio-demographic information, broad coverage of sleep habits (eg, sleep-wake schedule, sleep hygiene), physical health queries, and questions related to sleep symptoms and sleep history.

\section{SDSC}

The $\operatorname{SDSC}^{35}$ is a parent-report instrument for evaluating sleep disturbances in school-aged children. The tool is a 26-item Likert-type rating scale with six subscales (sleep-wake transition disorders, disorders of initiating and maintaining sleep, disorders of arousal/nightmares, sleep hyper-hidrosis, disorders of excessive somnolence, and sleep breathing disorders) with a cut-off score of 39. According to Bruni and colleagues, ${ }^{35}$ internal consistency was high in controls $(0.79)$ and at a satisfactory level in clinical subjects (0.71). The test/re-test reliability was adequate for the total score (0.71) and the single item scores.

\section{Sleep diary (according to Richman and colleagues)}

The sleep diary ${ }^{38}$ was used as a common instrument for measuring sleep difficulties. Minde and colleagues refer

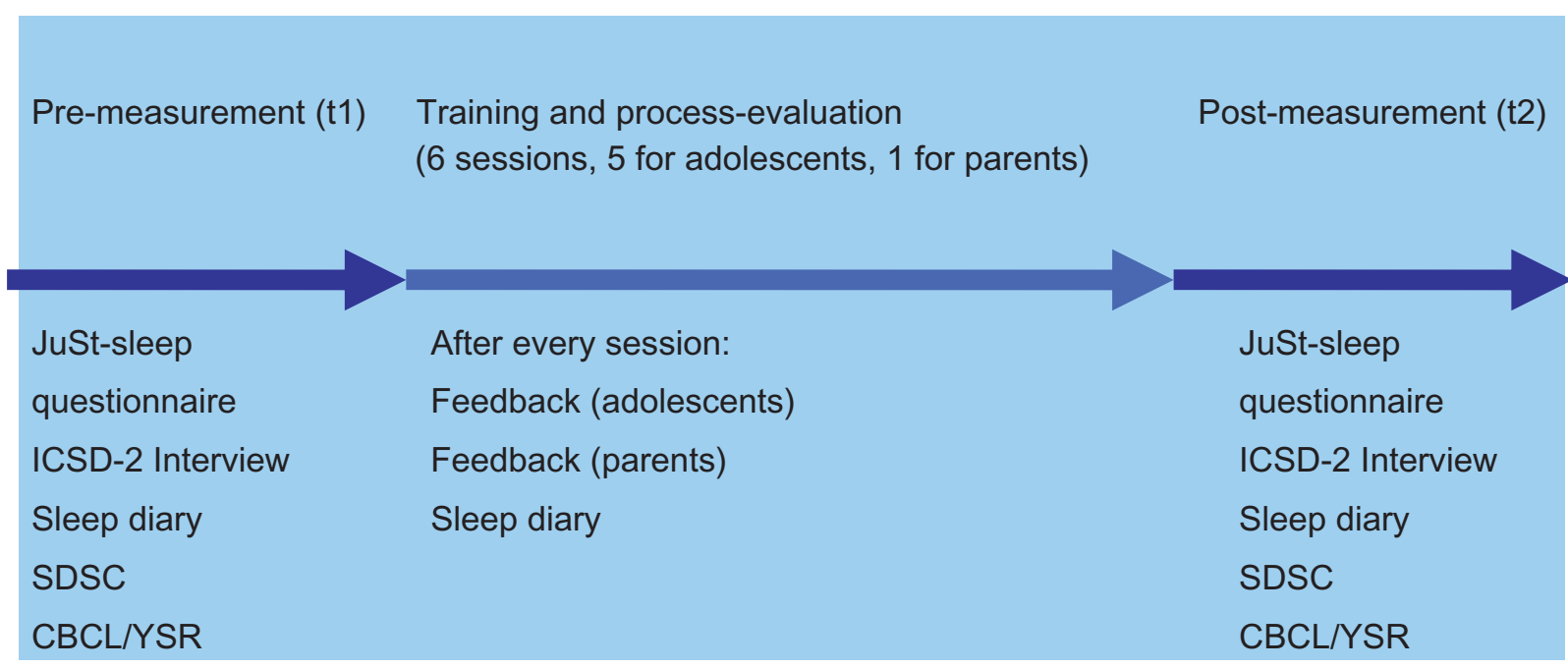

Figure I Diagnostic procedure.

Abbreviations: ICSD-2, International Classification of Sleep Disorders 2nd edition; SDSC, Sleep Disturbance Scale for Children; CBCL, Child Behavior Checklist; YSR, Youth Self Report. 
Table 3 Feedback from the adolescents about the acceptance and structure of the JuSt-training

\begin{tabular}{|c|c|c|c|c|}
\hline $\mathbf{N r}$ & Questions & Min & Max & Mean (SD) \\
\hline I & Today's topic was very interesting & $\mathrm{I}$ & 4 & $3.39(0.78)$ \\
\hline 2 & The theoretical and practical knowledge was clearly demonstrated & 3 & 4 & $3.78(0.42)$ \\
\hline 3 & My individual situation was sufficiently taken into account & 2 & 4 & $3.60(0.58)$ \\
\hline 4 & I received answers to my questions & 3 & 4 & $3.91(0.29)$ \\
\hline 5 & I will carry new ideas over into my everyday life & 2 & 4 & $3.69(0.56)$ \\
\hline 6 & Sufficient practice opportunities were offered & I & 4 & $3.00(1.00)$ \\
\hline 7 & I received concrete support for the transition into everyday life & 0 & 4 & $3.48(0.95)$ \\
\hline 8 & I felt very comfortable with this group today & 3 & 4 & $3.78(0.42)$ \\
\hline 9 & There was enough opportunity for exchange within the group & 0 & 4 & $3.04(1.14)$ \\
\hline 10 & The training motivated me to keep working on this topic & 2 & 4 & $3.43(0.79)$ \\
\hline II & The training helped me to solve my sleep problems & 2 & 4 & $3.52(0.59)$ \\
\hline
\end{tabular}

Coding: 0 = not at all; $\mathrm{I}=$ hardly; 2 = not sure; 3 = quite a bit; 4 = extremely.

to a Cronbach's alpha of 0.77 for internal consistency. ${ }^{39}$ Adolescents were asked to fill out a 2-week sleep diary about their bedtime, rising time, duration of bedtime procedure, sleep onset latency, frequency, and duration of night waking.

\section{Feedback questionnaire for adolescents}

The feedback questionnaire was developed a) to evaluate the acceptance of the treatment and b) to evaluate the content of the treatment. The questionnaire consisted of 19 questions about the treatment.

\section{Feedback questionnaire for parents}

This feedback questionnaire was constructed to evaluate the acceptance and the content of the treatment. The questionnaire consisted of 5 questions about the treatment and materials.

\section{Youth Self Report (YSR)}

The YSR ${ }^{40}$ is derived from the Child Behavior Checklist/4-18 $(\mathrm{CBCL}){ }^{41}$ It is a questionnaire for adolescents between the ages of 11 and 18. The YSR contains 112 items that measure 8 sub-scale symptoms: withdrawn, somatic complaints, anxiety and depression, social problems, thought problems, attention problems, aggressive behavior, and delinquent behavior. ${ }^{40}$ The first three subscales are referred to as 'internalizing' and the following two as 'externalizing'. The remaining three scales are categorized as 'neither internalizing nor externalizing'. Overall behavioral and emotional functioning is measured by the total problem scale. An adolescent selects his or her response from 0 (not true) to 2 (very true or often true).

\section{Statistical analyses}

All data were included. Prior to analysis, the data for all variables were inspected for missing values. All quantitative data analyses were conducted using the Statistical Package for Social Sciences (SPSS Version 16 for Windows, SPSS Inc, Chicago, IL, USA). Paired-samples $t$-tests were used to investigate baseline differences between pre- and post-treatment. An alpha level of 0.05 was set. Effect sizes using Cohen's d were calculated and reported. ${ }^{42}$ Program evaluation (feedback-questionnaires) was calculated with Mean and SD as well as Min and Max.

\section{Results Acceptance}

Program attendance rates were high $(88.89 \%$ attended all sessions, $11.11 \%$ missed 1 session). To evaluate the acceptance of the psychological treatment the questionnaire was filled out after every session by the adolescents. They rated

Table 4 Feedback from the adolescents about the contents of the JuSt-training

\begin{tabular}{|c|c|c|c|c|}
\hline Nr & Questions & Min & Max & Mean (SD) \\
\hline I & Information about healthy sleep was helpful & $\mathrm{I}$ & 4 & $3.47(0.86)$ \\
\hline 2 & Information about disturbed and sleep disorders was helpful & 2 & 4 & $3.35(0.70)$ \\
\hline 3 & Information about sleep hygiene was helpful & 2 & 4 & $3.47(0.62)$ \\
\hline 4 & Information about sleep environment was helpful & 0 & 4 & $3.26(1.15)$ \\
\hline 5 & Information about coping with sleep disturbing cognitions and sorrows was helpful & 0 & 4 & $3.18(1.33)$ \\
\hline 6 & Information about coping with stress was helpful & $\mathrm{I}$ & 4 & $3.18(0.95)$ \\
\hline 7 & Learning hypnotherapeutic strategies was helpful & 0 & 4 & $3.00(1.17)$ \\
\hline 8 & Learning PMR was helpful & 0 & 4 & $3.23(1.15)$ \\
\hline
\end{tabular}

Coding: 0 = not at all; I = hardly; 2 = not sure; 3 = quite a bit; $4=$ extremely.

Abbreviation: PMR, progressive muscle relaxation. 
Table 5 Feedback from the parents about the JuSt-training

\begin{tabular}{|c|c|c|c|c|}
\hline Nr & Questions & Min & Max & Mean (SD) \\
\hline I & The manual was clear & 3 & 3 & $3.00(0.00)$ \\
\hline 2 & The parental strategies explained were useful & 2 & 3 & $2.87(0.35)$ \\
\hline 3 & The explained strategies were successful & I & 3 & $1.60(0.89)$ \\
\hline 4 & The explained strategies were unnecessary & 0 & 0 & $0.00(0.00)$ \\
\hline 5 & I received ideas on how to support my child in overcoming the sleep problems in future & I & 3 & $2.17(0.75)$ \\
\hline
\end{tabular}

Coding: 0 = not at all; $\mathrm{I}=$ hardly; 2 = not sure; 3 = quite a bit; 4 = extremely.

all questions on the structure of the sessions over the mean of $3.00(0=$ not at all, $4=$ extremely $)$. Nearly all participants indicated that their questions about sleep and sleep difficulties were answered $(M=3.91)$. They rated the clarity of the theoretical and practical knowledge high $(\mathrm{M}=3.78)$ and felt comfortable with the group over the treatment $(\mathrm{M}=3.78)$. Table 3 shows the results in detail.

Furthermore, questions about the content of the session were asked after the training. The adolescents considered the information about sleep hygiene as most helpful $(M=3.47)$ followed by the information about healthy and disturbed sleep $(\mathrm{M}=3.35)$. Table 4 shows the results in detail.

The parents became involved in the training for a single group session. To obtain the parents' evaluation they received a feedback questionnaire too. The clarity of the manual received the highest ratings by the parents $(\mathrm{M}=3.00)$ followed by the parental strategies they had learned $(\mathrm{M}=2.87)$. Table 5 shows the results.

\section{SDSC}

We conducted a $t$-test for dependent samples on the Total Score as well as on the subscales of the SDSC as well as the sleep diary data as dependent variables. At post-measurement (t2) the adolescents showed significant improvements in the SDSC-subscale disorders of initiating and maintaining sleep

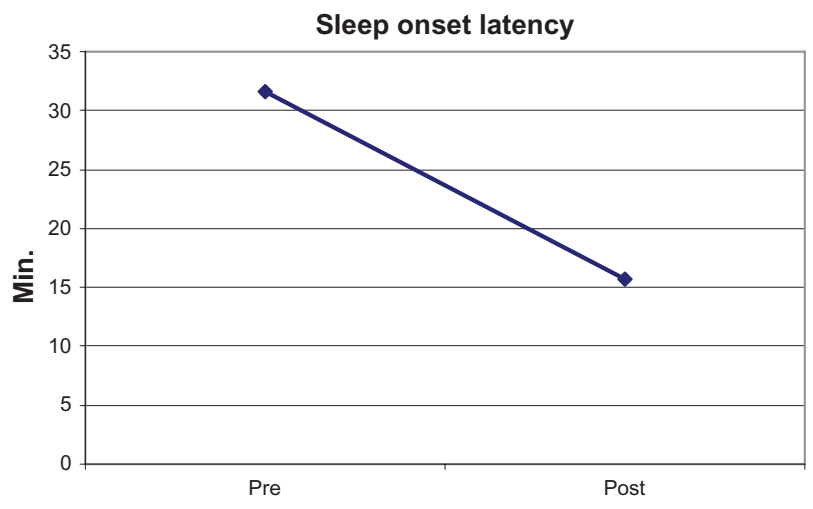

Figure 2 Sleep onset latency of adolescents before (pre-) and after (post-) treatment (JuSt-training).
(DIMS) from 19.47 (SD 4.84) to 12.76 (SD 2.70) $(\mathrm{t}(17)=4.98$, $P \leq 0.001)$.

\section{Sleep diary data}

For this pilot study the sleep diary data were assessed with regard to the adolescents' sleep onset time as well as sleep efficiency as this is a typical symptom of insomnia and one of the most addressed topics of the treatment program. At postmeasurement $(\mathrm{t} 2)$ the sleep diary data revealed a significant decrease in the sleep onset latency from $M=32$ minutes ( $\mathrm{SD}=18.16)$ before to $\mathrm{M}=16$ minutes $(\mathrm{SD}=10.88)$ after treatment $(\mathrm{t}(17)=4.26, P \leq 0.001)$ as shown in Figure 2 .

Furthermore, sleep efficiency increased significantly from $88.7 \%$ before to $94 \%$ after the treatment $(\mathrm{t}(17)=-3.55$, $P \leq 0.002$ ), as shown in Figure 3, and total sleep time significantly increased from $\mathrm{M}=493.06$ minutes before to $\mathrm{M}=520.84$ minutes after the training $(\mathrm{t}(17)=-2.57$, $P \leq 0.018$ ) as shown in Figure 4.

After treatment the adolescents felt significantly more rested $(\mathrm{M}=6.5(\mathrm{SD}=2.39)$ to $3.25(\mathrm{SD}=2.08),(\mathrm{t}(17)=3.27$; $P=0.005)$ ). In addition, the adolescents reported a significant decrease in concerns about their sleep after the treatment $(\mathrm{M}=2.31(\mathrm{SD}=1.62)$ to $0.68(\mathrm{SD}=0.95),(\mathrm{t}(17)=3.72$; $P=0.002)$ ).

Finally, the adolescents showed a significant increase in their emotional well-being. The sum-score of the Youth Self Report Rating showed a significant decrease after the training (from 62.11 before to 58.70 after the training $(\mathrm{t}(17)=4.75$; $P=0.044)$ ).

\section{Discussion}

The present study was the first to implement a multimodal group treatment for adolescents between the ages of 11 and 16 years. In contrast to previous studies ${ }^{43-45}$ this was a clinical study with adolescents suffering from insomnia. The goal was to develop and evaluate the JuSt-training with regard to acceptance, feasibility, and effectiveness.

First results show that the acceptance of the treatment was high for the adolescents as well as for their parents. The 


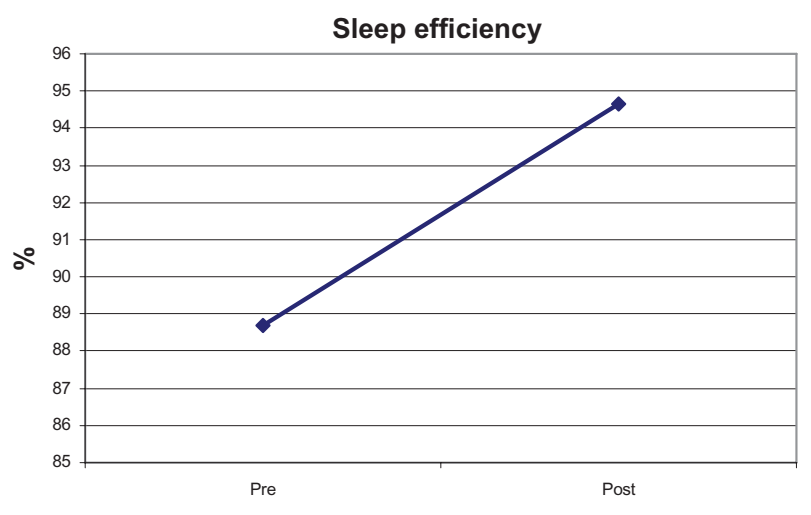

Figure 3 Sleep efficiency of adolescents before (pre-) and after (post-) treatment (JuSt-training).

adolescents assessed the answers to their sleep-related questions as very helpful $(\mathrm{M}=3.91, \mathrm{SD}=0.29)$. Furthermore, sleep hygiene was appraised as very helpful to overcome the sleep problems $(\mathrm{M}=3.47, \mathrm{SD}=0.62)$. Parents reported that they could clearly understand the presented parental strategies $(\mathrm{M}=3.00, \mathrm{SD}=0.00)$ and categorized them as helpful $(\mathrm{M}=2.87, \mathrm{SD}=0.35)$. Unlike other attempts at engaging adolescents in group therapy for sleep problems ${ }^{46}$ the present study had a considerably higher retention rate (100\% vs 42\%) and no adolescent dropped out after beginning the treatment.

The treatment's effectiveness is reflected in several parameters. The adolescents showed a significantly shorter sleep onset latency after the treatment. Furthermore, total sleep time as well as sleep efficiency were significantly higher after the treatment although going to bed earlier is unpopular with adolescents..$^{25}$ The group intervention enabled the adolescents to increase their knowledge about relevant sleep-related information as well as coping mechanisms, such as cognitive restructuring and changing their sleep-related behavior. The adolescents not only gained more knowledge

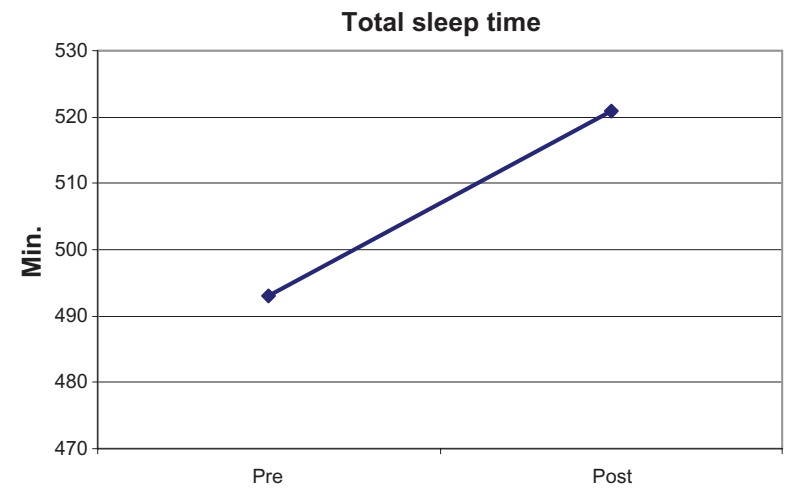

Figure 4 Total sleep time of adolescents before (pre-) and after (post-) treatment (JuSt-training). about sleep and sleep hygiene ${ }^{45}$ but also more skills to resolve their sleep problems by applying behavioral as well as hypnotherapeutic strategies. Keeping in mind that about $67 \%$ reported sleep problems during infancy and childhood, and $83.3 \%$ of the adolescents indicated to have been suffering from insomnia symptoms for more than a year, those results are important. In contrast to other studies, there was also a significant effect on daytime parameters, such as being worried about sleep or daytime sleepiness. ${ }^{25}$

The program offered opportunities for interactive learning experiences as a group intervention ${ }^{46}$ as well as hands-on activities and homework to transfer knowledge into practice which was required from adolescents with sleep problems in other studies. ${ }^{25}$ Another positive aspect of this study is that the evaluation was enhanced by sleep diaries to monitor sleep and thus increase the accuracy of the adolescents' own reports. ${ }^{47}$

However, this study was a feasibility project with limitations. The number of adolescents participating in the study was not very high. Furthermore, objective data of sleep problems were not available and the adolescents had no co-morbid mental disorder such as ADHD although most of them had a second or even third sleep disorder. Finally, the investigation was based on pre-/post-measurement, ie, the effects of the treatment have yet to be proven by a control-group design.

\section{Conclusion and future perspectives}

The present study showed the first effects of a structured multimodal treatment program for adolescents between the ages of 11 and 16 years. The treatment was well accepted by the adolescents and their parents and led to significant improvements in the sleep problems. Despite the study's limitations, this intervention program is a promising treatment model for adolescents with sleep problems, and future research should implement the program in a control-group design.

\section{Disclosure}

This was not an industry-supported study. The authors have indicated no financial conflicts of interest.

\section{References}

1. Acebo C, Wolfson AR. Inadequate sleep in children and adolescents. In: Kushida CA, editor. Sleep Deprivation. New York: Marcel Dekker; 2005;151-171.

2. Stores G. Children's sleep disorders: modern approaches, developmental effects, and children at special risk. Dev Med Child Neurol. 1999;41(8): 568-573.

3. Liu X, Uchiyama M, Shibui K, et al. Diurnal preference, sleep habits, circadian sleep propensity and melatonin rhythm in healthy human subjects. Neurosci Lett. 2000;280(3):199-202.

4. Gau SF, Soong WT. The transition of sleep-wake patterns in early adolescence. Sleep. 2003;26(4):449-454. 
5. Adam EK, Snell EK, Pendry P. Sleep timing and quantity in ecological and family context: a nationally representative time-diary study. J Fam Psychol. 2007;21(1):4-19.

6. Roberts RE, Roberts CR, Chen IG. Impact of insomnia on future functioning of adolescents. J Psychosom Res. 2002;53(1):561-569.

7. Ohayon MM, Roberts RE. Comparability of sleep disorders diagnoses using DSM-IV and ICSD classifications with adolescents. Sleep. 2001; 24(8):920-925.

8. Johnson EO, Roth T, Schultz L, Breslau N. Epidemiology of DSM-IV insomnia in adolescence: lifetime prevalence, chronicity, and an emergent gender difference. Pediatrics. 2006;117(2):e247-e256.

9. Ohayon MM, Roberts RE, Zulley J, Smirne S, Priest RG. Prevalence and patterns of problematic sleep among older adolescents. $J$ Am Acad Child Adolesc Psychiatry. 2000;39(12):1549-1556.

10. Kirmil-Gray K, Eagleston JR, Elizabeth G, Thoresen E. Sleep disturbance in adolescents: Sleep quality, sleep habits, beliefs about sleep, and daytime functioning. $J$ Youth Adolesc. 1984;13(5):375-384.

11. Patten CA, Choi WS, Gillin JC, Pierce JP. Depressive symptoms and cigarette smoking predict development and persistence of sleep problems in US adolescents. Pediatrics. 2000;106(2):E23.

12. Ohayon MM, Roth T. Place of chronic insomnia in the course of depressive and anxiety disorders. $J$ Psychiatr Res. 2003;37(1):9-15.

13. Tynjälä J, Kannas L, Välimaa R. How young Europeans sleep. Health Educ Res. 1993;8(1):69-80.

14. Vignau J, Bailly D, Duhamel A, Vervaecke P, Beuscart R, Collinet C. Epidemiologic study of sleep quality and troubles in French secondary school adolescents. J Adolesc Health. 1997;21(5):343-350.

15. Morrison DN, McGee R, Stanton WR. Sleep problems in adolescence. J Am Acad Child Adolesc Psychiatry. 1992;31(1):94-99.

16. Wolfson AR, Carskadon MA. Sleep schedules and daytime functioning in adolescents. Child Dev. 1998;69(4):875-887.

17. Kaneita Y, Ohida T, Uchiyama M, et al. The relationship between depression and sleep disturbances: a Japanese nationwide general population survey. J Clin Psychiatry. 2006;67(2):196-203.

18. O’Brien EM, Mindell JA. Sleep and risk-taking behavior in adolescents. Behav Sleep Med. 2005;3(3):113-133.

19. Goldstein TR, Bridge JA, Brent DA. Sleep disturbance preceding completed suicide in adolescents. J Consult Clin Psychol. 2008;76(1): 84-91.

20. Roberts RE, Roberts CR, Duong HT. Chronic insomnia and its negative consequences for health and functioning of adolescents: a 12-month prospective study. J Adolesc Health. 2008;42(3):294-302.

21. Wiggs L, France K. Behavioural treatments for sleep problems in children and adolescents with physical illness, psychological problems or intellectual disabilities. Sleep Med Rev. 2000;4(3):299-314.

22. Bootzin RR, Stevens SJ. Adolescents, substance abuse, and the treatment of insomnia and daytime sleepiness. Clin Psychol Rev. 2005;25: 629-644.

23. Rossi CM, Campbell AL, Vo OT, Marco CA, Wolfson AR. Middle school sleep-smart program: a pilot evaluation. Sleep. 2002;25:A279.

24. National Space Biomedical Research Institute and Baylor College of Medicine, 2007. Available from: http://old.nhlbi.nih.gov/health/public/ sleep/starslp/about.htm. Accessed Nov 62010.

25. Moseley L, Gradisar M. Evaluation of a school-based intervention for adolescent sleep problems. Sleep. 2009;32(3):334-341.

26. Schlarb AA. JuSt - Therapeutenmanual zur Behandlung von Jugendlichen (10-16 Jahre) mit Schlafstörungen. Stuttgart: Kohlhammer Verlag; In press.
27. Unbehaun T, Spiegelhalder K, Hirscher V, Riemann D. Management of insomnia: update and new approaches. Nature Sci Sleep. 2010;2:127-138.

28. Stepanski EJ, Wyatt JK. Use of sleep hygiene in the treatment of insomnia. Sleep Med Rev. 2003;7:215-225.

29. Manber R, Bootzin RR, Acebo C, Carskadon MA. The effects of regularizing sleep-wake schedules on daytime sleepiness. Sleep. 1996;19: 432-441.

30. Dahl RE, Lewin DS. Pathways to adolescent health sleep regulation and behavior. $J$ Adolesc Health. 2002;31:175-184.

31. Schlarb AA, Gulewitsch MD. Wenn der Sandmann kommt - wirkt Hypnotherapie bei Kindern mit Schlafstörungen? Hypnose. In press (2011). Hypnose-ZHH 6(1+2).

32. Morin CM, Hauri PJ, Espie CA, Spielman AJ, Buysse DJ, Bootzin RR. Nonpharmacologic treatment of chronic insomnia. An American Academy of Sleep Medicine Review. Sleep. 1999;22(8): 1134-1156.

33. American Psychiatric Association. Diagnostic and Statistical Manual of Mental Disorders. 4th ed. Text Revision. Washington, DC: APA; 2000.

34. American Academy of Sleep Medicine. International Classification of Sleep Disorders: Diagnostic and Coding Manual, ICSD-2. 2nd ed. Newton, MA: American Academy of Sleep Medicine; 2005.

35. Bruni O, Ottaviano S, Guidetti V, et al. The Sleep Disturbance Scale for Children (SDSC). Construction and validation of an instrument to evaluate sleep disturbances in childhood and adolescence. J Sleep Res. 1996;5(4):251-261.

36. Di Nardo PA, Barlow DH. Anxiety Disorders Interview ScheduleRevised (ADIS-R). Graywind Publications, New York, 1988.

37. Unnewehr S, Schneider S, Margraf J. Kinder-DIPS: Diagnostisches Interview bei psychischen Störungen im Kindes- und Jugendalter. Springer, Berlin, 1995.

38. Richman N, Douglas J, Hunt H, Lansdown R, Levere R. Behavioural methods in the treatment of sleep disorders - a pilot study. $J$ Child Psychol Psychiatry. 1985;26(4):581-590.

39. Minde K, Popiel K, Leos N, Falkner S, Parker K, Handley-Derry M. The evaluation and treatment of sleep disturbances in young children. J Child Psychol Psychiatry. 1993;34(4):521-533.

40. Achenbach TM. Manual for the Youth-Self Report and 1991 Profile. University of Vermont, Department of Psychiatry; Burlington VT: 1991b.

41. Achenbach TM. Manual for the Child Behavior Checklist/4-18 and 1991 Profile. University of Vermont, Department of Psychiatry; Burlington VT: 1991a.

42. Cohen J. Statistical Power Analysis for the Behavioral Sciences (2nd ed). Lawrence Erlbaum Associates; Hillsdale, NJ: 1988.

43. Rossi CM, Campbell AL, Vo OT, Marco CA, Wolfson AR. Middle school sleep-smart program: a pilot evaluation. Sleep. 2002;25:A279.

44. Vo OT, LeChasseur K, Wolfson A, Marco C. Sleepy pre-teens: second pilot of Sleep-Smart Program in 7th graders. Sleep. 2003;26:A411.

45. de Sousa IC, Araujo JF, de Azevedo CVM. The effect of a sleep hygiene education program on the sleep-wake cycle of Brazilian adolescent students. Sleep Biol Rhythms. 2007;5:251-258.

46. Bootzin RR, Stevens SJ. Adolescents, substance abuse, and the treatment of insomnia and daytime sleepiness. Clin Psychol Rev. 2005;25: 629-644.

47. Buysse DJ, Ancoli-Israel S, Edinger JD, Lichstein, KL, Morin CM. Recommendations for a standard research assessment of insomnia. Sleep. 2006;29:1155-1173.
Nature and Science of Sleep

\section{Publish your work in this journal}

Nature and Science of Sleep is an international, peer-reviewed, open access journal covering all aspects of sleep science and sleep medicine, including the neurophysiology and functions of sleep, the genetics of sleep, sleep and society, biological rhythms, dreaming, sleep disorders and therapy, and strategies to optimize healthy sleep. The journal welcomes

\section{Dovepress}

original research, clinical \& epidemiological studies, reviews \& evaluations, case reports and extended reports. The manuscript management system is completely online and includes a very quick and fair peerreview system, which is all easy to use. Visit http://www.dovepress.com/ testimonials.php to read real quotes from published authors. 